\title{
LA TRANSFORMACIÓN \\ DE LA CULTURA ORGANIZACIONAL DEL FUERO PENAL SANTAFESINO, DURANTE EL PROCESO DE CAMBIO HACIA UN SISTEMA ADVERSARIAL
}

\author{
Tesista \\ José Luis Longo Gasser \\ Director de tesis \\ Gustavo Edgardo Blutman
}

Durante los ‘90 del siglo pasado en Argentina y Latinoamérica, y en la década anterior en Estados Unidos y Europa principalmente, se introdujeron fuertes reformas en la estructura de los Estados, las cuales produjeron cambios en la organización de los mismos. Los diferentes países latinoamericanos efectuaron modificaciones en sus marcos jurídicos internos y para ello introdujeron reformas constitucionales de envergadura, las que incluyeron entre sus ejes reformistas lo relativo a la independencia de la justicia y las nuevas formas de participación ciudadana. Estos temas fueron alentados fundamentalmente por los organismos internacionales a fin de mejorar la eficiencia en el empleo de los recursos disponibles en el seno de los Poderes Judiciales

En este estudio se describe el proceso de reforma del sistema procesal penal que introdujo la provincia de Santa Fe a partir del 10 de febrero de 2014. Se identifican los principales cambios organizacionales que se implementaron y se analizaron las características de la cultura organizacional del fuero penal, observada tanto en el sistema inquisitivo como durante el actual sistema adversarial.

Si bien el tratamiento de los temas cambio y cultura organizacional no es novedoso, se realizó un abordaje que los fusionó, efectuando una orientación del trabajo a la reinvención organizacional de los sistemas penales producto de las reformas administrativas en los sistemas judiciales.

Nos fijamos como objetivo general el analizar los impactos en la cultura organizacional durante los procesos de cambio organizacional en el ámbito de la justicia penal y como objetivos específicos: describir el proceso de reforma del sistema procesal penal de la provincia de Santa Fe, identificar los principales cambios organizacionales en los fueros penales de aquellas provincias argentinas que hayan implementado sistemas procesales penales de tipo adversarial y analizar las características de la cultura organizacional del 
fuero penal santafesino antes y después del cambio del sistema procesal.

Nuestra unidad de análisis fue el fuero penal del Poder Judicial de la provincia de Santa $\mathrm{Fe}$, específicamente la primera instancia en el Distrito Judicial $N^{\circ} 1$. Nos inclinamos por esta elección por la representatividad de la provincia de Santa Fe en el ámbito nacional, sea por razones demográficas como también por la dimensión de su Poder Judicial en comparación con el resto de las sedes judiciales que implementaron sistema de enjuiciamiento adversarial y en lo particular, el Distrito Judicial $N^{\circ} 1$ se escogió por ser la segunda sede en importancia dentro del territorio provincial, uno de los dos distritos que posee primera y segunda instancia funcionando por separado, y debido a la facilidad de acceso a la unidad de análisis.

Nuestras preguntas de investigación fueron ¿la modificación del sistema procesal penal ha sido un verdadero cambio organizacional?

¿Qué tipo de cambios estructurales se han implementado en el fuero penal? ¿El cambio de sistema ha traído una modificación en la cultura organizacional del fuero penal santafesino?

Con relación a la investigación a desarrollar, esta al inicio fue de tipo exploratoria, mediante el proceso de revisión de material e información existente, intentando profundizar sobre temas acerca de los cuales se desconocía, y esto nos permitió obtener los datos necesarios para progresar en nuestro trabajo. En un siguiente paso, el estudio fue de tipo descriptivo, y allí se buscó especificar sobre lo observado.

Se utilizaron instrumentos tanto cuantitativos como cualitativos de recolección de datos, los últimos atendiendo a que en nuestro caso de estudio se recabó información de valores y presunciones culturales invisibles a la simple observación.
Mediante el trabajo de campo que se realizó a los miembros que pertenecen actualmente al sistema adversarial y que habían integrado algún juzgado del proceso inquisitivo, se procedió a recolectar los elementos cualitativos y cuantitativos con los cuales se efectuó un análisis comparativo de la cultura organizacional presente en cada uno de los sistemas de enjuiciamiento.

Para dar respuesta a los objetivos específicos, primariamente se desarrolló un trabajo exploratorio en el que encontramos que respecto de los cambios de los sistemas procesales en las diferentes provincias en las que se implementó, incluida Santa Fe, en ninguno de los casos se dio en un solo paso o movimiento sino que, por el contrario, el recorrido histórico de la legislación procesal evidenció que los cambios normativos tuvieron como antecedente principal el camino iniciado por promotores latinoamericanos del sistema adversarial y luego las reformas constitucionales que abrieron la puerta a la inclusión de la nueva legislación procesal. Lo siguiente fue la modificación de la estructura organizativa de los Poderes Judiciales y la generación de una nueva gestión de justicia. Identificamos que estos procesos, que no suceden de manera reiterada por la complejidad intrínseca de su implementación, son por lo tanto de naturaleza discontinua, y por el origen exógeno y la profundidad de la reforma son disruptivos.

Respecto a nuestras preguntas que encaminaron el trabajo, y sobre la base de lo analizado, concluimos que, por la naturaleza y origen del cambio, por la transformación sustancial de la estructura organizacional del fuero penal, por la necesidad de adoptar nuevos conocimientos, habilidades o actitudes por parte de sus integrantes, la modificación del sistema procesal entra en nuestra definición de cambio organizacional. 
Concluimos que los resultados obtenidos nos señalarían que los miembros identificaron al sistema inquisitivo con el modelo de organización burocrático tradicional, que funcionaba en una estructura con profunda distancia de poder, escasez de innovación y baja tolerancia a la incertidumbre, que poseía características de un tipo de cultura altamente burocratizada y apática. Con relación al sistema adversarial, los datos indicarían una identificación con el modelo de organización posburocrático, en el cual existe una mejor distribución de poder y con integrantes de la oficina que poseen mayor tolerancia a la incertidumbre.

Finalmente como aportes al conocimiento nuestro trabajo destaca la importancia de dar continuidad a la tarea realizada haciendo foco en los siguientes aspectos: estudiar el impacto del cambio en otra sede judicial, realizar nuevos monitoreos entre los miembros de la organización analizada, estudiar una nueva variable el "liderazgo" y estudiar la "cultura organizacional» como variable independiente.

\section{PARA CITAR ESTE ARTÍCULO:}

Longo Gasser, J.L. (2018). "Recensión de tesis: “La transformación de la cultura organizacional del fuero penal santafesino, durante el proceso de cambio hacia un sistema adversarial" ", DAAPGE, año 18, № 31 (jul-dic), 2018, pp. 179-181. Santa Fe, Argentina: UNL. 